\title{
Hepatocytic precursor (stem-like) WB-F344 cells reduce tumorigenicity of hepatoma CBRH-7919 cells via TGF-B/Smad pathway
}

\author{
WEI-QING LI ${ }^{*}$, YI-MING LI ${ }^{2 *}$, JIA GUO ${ }^{3}$, YU-MING LIU ${ }^{4}$, XIAO-QUN YANG ${ }^{1}$, \\ HUI-JUAN GE ${ }^{1}$, YI XU ${ }^{1}$, HUI-MIN LIU ${ }^{1}$, JIN HE$^{1}$ and HONG-YU YU ${ }^{1}$
}

\begin{abstract}
Departments of ${ }^{1}$ Pathology and ${ }^{2}$ Neurosurgery, Changzheng Hospital, The Second Military Medical University, Shanghai 200003; ${ }^{3}$ Department of Ultrasonography, Eastern Hepatobiliary Surgery Hospital, The Second Military

Medical University, Shanghai 200438; and ${ }^{4}$ Naval Medical Institute, Shanghai 200433, P.R. China
\end{abstract}

Received December 21, 2009; Accepted March 10, 2010

DOI: 10.3892/or_00000801

\begin{abstract}
Hepatic stem cells (HSCs) are involved in repair of liver injury. Stem cells may have inhibitory effects on tumor cell growth and apoptosis. However, it is unknown whether HSCs regulate the biological functions of hepatocarcinoma cells, especially tumor cell growth and apoptosis. The present study was designed to determine the effects of hepatocytic precursor (stem-like) WB-F344 cells on the growth and apoptosis of hepatoma CBRH-7919 cells. Using a Transwell chamber culture system, we co-cultured WB-F344 cells and CBRH-7919 cells in serum-free conditioned medium

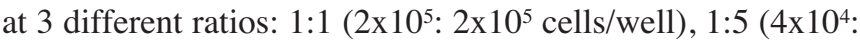

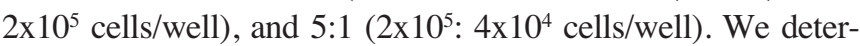
mined the effects of stem cells on tumor cells using in vivo xenograft assay in nude mice and determining gene expression by RT-PCR and Western blot analyses. With the increment proportion of the WB-F344 cells in the co-culture system, tumor formation was inhibited in nude mice. Moreover, downregulation of bone morphogenetic protein 4 (BMP4), Bcl-2, and c-Myc and upregulation of PTEN also occurred along with the inhibitory effects. Western blotting showed that the TGF-3/Smad pathway played a prominent role in tumor inhibition, which may have been mediated by the cytokines released from the stem cells. In conclusion, hepatocytic precursor (stem-like) WB-F344 cells inhibit the tumorigenicity of hepatoma CBRH-7919 cells, and the effect is mediated by TGF-B/Smad signaling pathway.
\end{abstract}

Correspondence to: Dr Hong-Yu Yu, Department of Pathology, Changzheng Hospital, The Second Military Medical University, 415 Fengyang Road, Shanghai 200003, P.R. China

E-mail: yuhongyu795@gmail.com

${ }^{*}$ Contributed equally

Key words: hepatocytic precursor (stem-like) cells, hepatoma cells, TGF-ß/Smad transduction pathway, apoptosis, inhibition

\section{Introduction}

Hepatocellular carcinoma (HCC), which is characterized by aggressive growth and poor prognosis, is the third leading cause of cancer-related mortality worldwide (1). Currently, no effective treatment is available for most HCC patients, except for surgical resection and liver transplantation in some patients whose disease is detected at a sufficiently early stage (2). The prognosis of patients with HCC remains extremely poor, with a 5-year survival rate of $<5 \%$ (3). Therefore, it is of interest and importance to develop novel approaches to better prevention and treatment of this disease.

Recently there has been increasing interest in the development of stem cell therapy for a variety of diseases, including cancers. Stem cells, derived from adult and embryonic sources, have great therapeutic potential. They are generally characterized by their capacity for self-renewal through asymmetrical cell division, long-term tissue reconstitution, multipotency for producing progeny in at least two lineages, and serial transplantability (4). In liver tissue, pre-existing mature hepatocytes have an extraordinary ability to regenerate after injury or resection $(5,6)$. Oval cells, one type of the candidate hepatic progenitor cells in rodent models, can differentiate to form both hepatocytes and cholangiocytes (7).

In a rodent hepatocarcinogenesis model, HCC is shown to originate from two cellular sources: mature hepatocytes (8) and hepatic progenitor cells (oval cells) (9-12). Kubota et al (13) reported that bone marrow cells (BMCs) fused with some oval cells but that the BMC-fused oval cells and BMCs did not have malignant potential in rats fed with the cholinedeficient, ethionine-supplemented diet. Another study suggested that the stem cell microenvironment may play an essential role in preventing carcinogenesis by providing signals to inhibit proliferation and to promote differentiation (14). Moreover, evidence is emerging that supports the premise that stem cells may serve as a vehicle for the transfer of genetic material in the treatment of patients with HCC, especially for those not suitable for resection, transplantation, ablation therapy, or arterial chemoembolization (15). In a clinical trial, treatment with stem cell differentiation stage factors 
showed inhibition of tumor growth in patients with HCC (14), but the underlying mechanisms are not fully understood.

The role of cellular transforming growth factors in carcinogenesis and stem cells is an emerging hot area of research. Transforming growth factor $\beta$ (TGF- $\beta$ ) is the prototype of a large family of structurally-related factors that regulate a diverse array of biological processes such as cell growth, differentiation, and apoptosis (16). The intracellular effectors of TGF- $\beta$ signaling, Smad proteins, are activated by receptors and translocated to the nucleus, where they regulate transcription of target genes (17). TGF- $\beta$ can be produced by hepatic non-parenchymal cells and acts as an inhibitory cytokine on hepatocytes (18) and as a negative regulator of hepatocyte proliferation after viral infection-induced chronic injury (19). In addition, TGF- $\beta$ induces apoptosis in several established human liver cancer cell lines, including HepG2 and HepG3 cells (20). Dysfunction of the members in the TGF- $\beta$ pathway, such as TGF- $\beta$ RII, bone morphogenetic proteins (BMPs), Smad2/3, and Smad4, may lead to progenitor/stem cell deregulation and, possibly, cancer formation (21).

In this study, we investigated the effects of hepatocytic precursor (stem-like) cells on HCC cells in vitro and in vivo using conditioned media, a co-culture system, and animal tumor transplantation models. We focused on the role of the TGF- $3 /$ Smad4 pathway in mediating HCC apoptosis, which may be induced by cytokines elicited from the liver epithelial stem-like cells. This study may have implications for the development of stem cell therapy for HCC.

\section{Materials and methods}

Cell culture. The diploid rat liver epithelial cell line WB-F344, derived from an adult male Fischer-344 rat (22), was obtained from Shanghai Cell Bank (Shanghai, China). Under suitable conditions, WB-F344 cells can differentiate into multiple cell lineages, including hepatocyte (23) and biliary (24) lineages. The rat hepatoma cell line CBRH-7919 was also obtained from Shanghai Cell Bank. The cells were cultured in Dulbecco's modified Eagle's medium/Ham's F12 medium (DMEM/F12, Gibco, Grand Island, NY, USA) supplemented with $10 \%$ fetal bovine serum (FBS, Gibco) in a humidified incubator containing $5 \% \mathrm{CO}_{2}$ at $37^{\circ} \mathrm{C}$.

Co-culture of WB-F344 stem cells and tumor cells. To determine the effects of stem cells on hepatoma cells, we co-cultured WB-F344 cells and CBRH-7919 cells in various ratios: 1:1 $\left(2 \times 10^{5}: 2 \times 10^{5}\right.$ cells/well $), 1: 5\left(4 \times 10^{4}: 2 \times 10^{5}\right.$ cells/

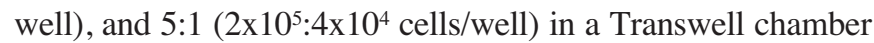
culture system $(4.0 \mu \mathrm{m}$ pore polycarbonate membrane insert, Corning, NY, USA ). The cells were co-cultured in a serumfree conditioned medium at $37^{\circ} \mathrm{C}$ with $95 \%$ air, $5 \% \mathrm{CO}_{2}$, and $100 \%$ humidity for 7 days (25) before use of the cells for subsequent assays, such as the nude mouse xenograft assay, flow cytometry analysis, and immunoblotting. The serumfree conditioned medium was composed of DMEM/F12 supplemented with $20 \mathrm{ng} / \mathrm{ml}$ of basic fibroblast growth factor (bFGF; Sigma, St. Louis, MO, USA), $20 \mathrm{ng} / \mathrm{ml}$ of epidermal growth factor (EGF; Sigma), and $20 \mu \mathrm{l} / \mathrm{ml}$ of B27 supplement (Life Technologies, Carlsbad, CA, USA).
Cell transplantation in nude mice. Nude mice (age: 4-6 weeks, obtained from the Institute of Zoology, Chinese Academy of Sciences, China) were kept under pathogen-free conditions in accordance with procedures and guidelines set by the Institutional Animal Care and Use Committee (IACUC) of the Second Military Medical University, Shanghai, China. The animals were divided into four groups (15/group): In groups A, B, and C, CBRH-7919 hepatoma cells in equal cell numbers $\left(1 \times 10^{6}\right)$ of the aforementioned different co-culture ratios $(1: 1,1: 5,5: 1)$, respectively, were subcutaneously injected into the flanks of the mice; animals in group D were injected with equal numbers $\left(1 \times 10^{6}\right)$ of CBRH-7919 cells and constituted the control group. At 35 days post-injection, five mice from each group were randomly selected and sacrificed for pathology analysis. Xenograft tumor tissues were fixed in $10 \%$ formaldehyde and processed using standard pathology section methods. The sections were stained using hematoxylin and eosin (H\&E) for histopathology analysis. Six tumorbearing mice were randomly selected for monitoring tumor growth, which was accomplished by measuring the length (L) and the width (W) of each tumor, and the volume was calculated by the formula of $\mathrm{V}=\left(\mathrm{L} \mathrm{x} \mathrm{W}^{2}\right) / 2$. Then, survival analysis of the remaining $(n=6$, selected randomly from mice which formed tumors) in each group were compared.

Flow cytometric analysis. Apoptotic hepatoma cells were detected by flow cytometry after staining with the ApoScreen Annexin V apoptosis kit (SouthernBiotech, Birmingham, AL, USA) in accordance with the manufacturer's instructions.

RT-PCR analysis. The mRNA expression levels of the selected genes, bone morphogenetic protein 4 (BMP4) (26), PTEN (27), Bcl-2 (28), and c-Myc (29), were examined using RTPCR analysis. Total RNA was prepared from hepatoma cells using TRIzol reagent (Invitrogen, Carlsbad, CA, USA). Reverse transcription of RNA was performed using the Superscript kit (Invitrogen) according to the manufacturer's instructions. The primers for the four rat genes were: BMP4: forward 5'-CGT TAC CTC AAG GGA GTG G-3' and reverse 5'-GCG ACG GCA GTT CTT ATT C-3'; PTEN: forward 5'-ACC ATA ACC CAC CAC AGC-3' and reverse 5'-CAC CAG TCC GTC CTT TCC-3'; BCL-2: forward 5'-CGG GAG AAC AGG GTA TGA-3' and reverse 5'-CAG GCT GGA AGG AGA AGA T-3'; and c-MYC: forward 5'-TCT CCG TCC TAT GTT GCG-3' and reverse 5'-GTC CTG GAT GAT GAT GTT CTT G-3'. ß-actin was used as a housekeeping gene and the primers were 5'-ACG TTG ACA TCC GTA AAG AC-3' and reverse 5'-GAA GGT GGA CAG TGA GGC-3'. Amplification was performed in a GeneAmp PCR system 9700 thermocycler (PE Applied Biosystems, Foster City, CA, USA). The PCR cycle was as follows: one cycle at $95^{\circ} \mathrm{C}$ for $30 \mathrm{sec}$, followed by 30 cycles at $95^{\circ} \mathrm{C}$ for $5 \mathrm{sec}$, at $60^{\circ} \mathrm{C}$ for $30 \mathrm{sec}$, with a final extension step at $72^{\circ} \mathrm{C}$ for $1 \mathrm{~min}$, using the Takara Bio kit (Osaka, Japan) according to the manufacturer's recommendations. The amplified product was loaded onto a $15 \mathrm{~g} / \mathrm{l}$ agarose gel containing ethidium bromide $(0.5 \mathrm{~g} / \mathrm{l})$ and visualized under UV light.

Western blot analysis. The protein expression levels of Smad4 and TGF- $\beta$ RII were analyzed by immunoblot analysis. Cell 
Table I. Transplantation in nude mice inoculated with CBRH-7919 cells.

\begin{tabular}{lccc}
\hline Groups & $\begin{array}{c}\text { The average day of the } \\
\text { tumor formation (D) }\end{array}$ & Average volume $\left(\mathrm{cm}^{3}\right)$ & Sacrificed on day \\
\hline A: (CBRH-7919:WB-F344 $=5: 1)$ & 21 & 6.63 & 35 \\
B: (CBRH-7919:WB-F344 =1:1) & 24 & 5.52 & 35 \\
C: (CBRH-7919:WB-F344 =1:5) & 26 & 4.26 & 35 \\
D: (Control group) & 16 & 7.34 & 35 \\
\hline
\end{tabular}

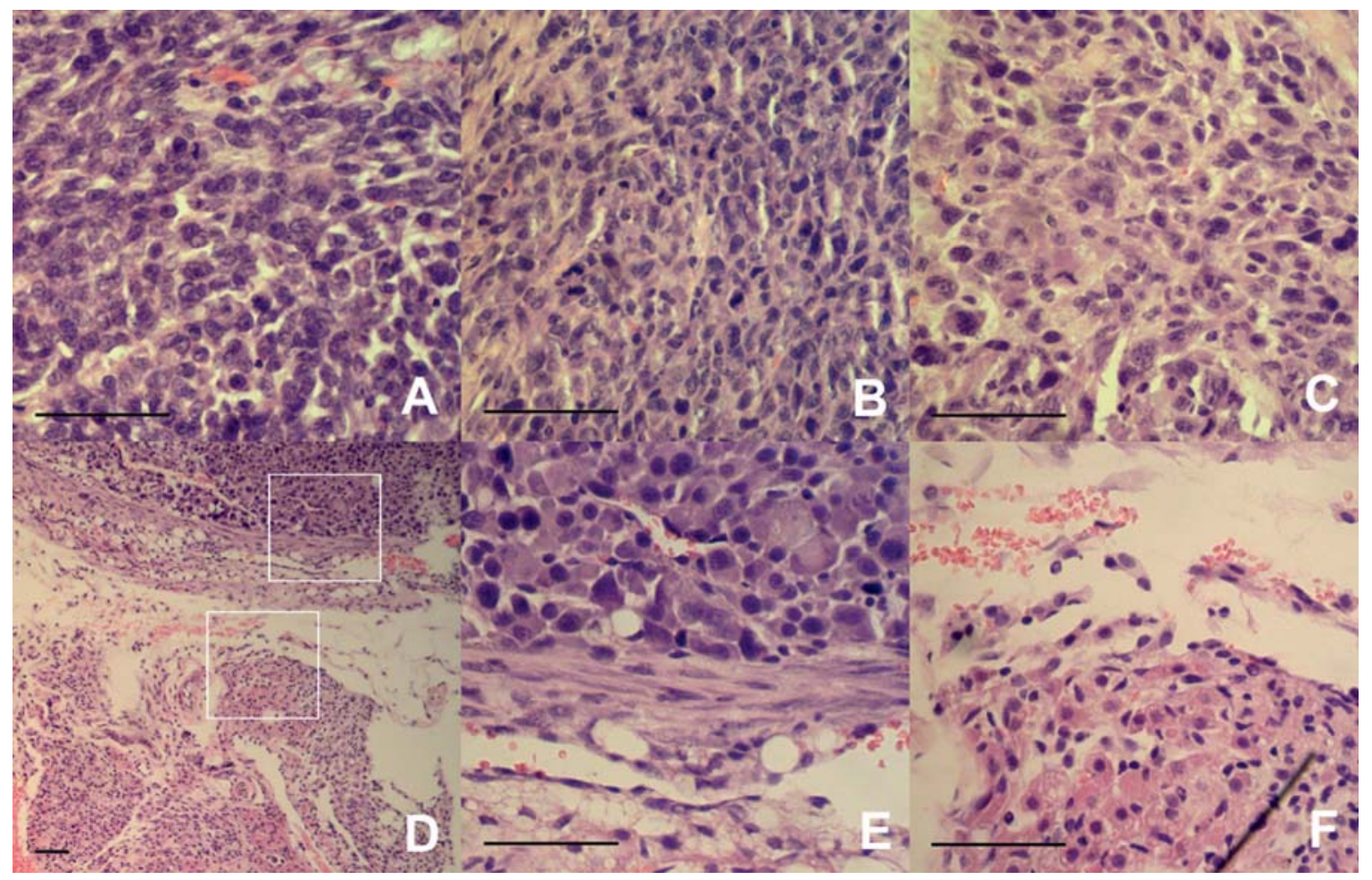

Figure 1. Inhibition of hepatoma cell tumor formation by WB-F344 hepatocytic precursor (stem-like) cells in nude mice. (A) CBRH-7919 control group (H\&E staining, x400); (B) CBRH-7919:WB-F344 = 5:1 group (H\&E staining, $x$ 400); (C) CBRH-7919:WB-F344 = 1:1 group (H\&E staining, x400). (D-F) CBRH-7919:WB-F344 = 1:5 group (H\&E staining; x100 for D; x400 for E and F). Scale bar: $100 \mu \mathrm{m}$.

lysate was prepared using RIPA buffer with protease inhibitors and quantified using the BCA protein assay (Pierce, IL, USA). Equal amounts of protein were separated by $10 \%$ sodium dodecyl sulfatepolyacrylamide gel electrophoresis (SDSPAGE) and electrophoretically transferred to polyvinylidene fluoride (PVDF) membranes (Millipore, IN, USA) using a minitrans-blot (Hercules, CA, USA). Membranes were then blocked with PBST (PBS with $0.05 \%$ Tween-20) containing $5 \%$ non-fat dry milk for $4 \mathrm{~h}$ and incubated with a rabbit polyclonal antibody against Smad4 (Cell Signaling Technology, MA, USA) or a rabbit polyclonal antibody against TGF-B RII (Cell Signaling Technology) for $24 \mathrm{~h}$ at $4^{\circ} \mathrm{C}$. Membranes were then washed with PBST and incubated with horseradish peroxidase conjugated goat anti-rabbit immunoglobulin $\mathrm{G}$ (IgG) for $1 \mathrm{~h}$. The blots were developed using an enhanced chemiluminescence (ECL) kit (Pierce). Protein was normalized with GAPDH (Santa Cruz Biotechnology, Santa Cruz, CA, USA).

\section{Results}

WB-F344 hepatocytic precursor (stem-like) cells inhibit tumor formation of hepatoma CBRH-7919 cells in nude mice. As illustrated in Table I, the control mice $(n=15)$ transplanted with CBRH-7919 cells alone formed tumors within 16-18 days (average tumor diameter $=3.4 \mathrm{~cm}$ on day 35 ). The mice injected with co-cultured CBRH-7919 hepatoma cells formed detectable tumors on days 19-28, and smaller tumors were formed (average tumor diameter $=1.9 \mathrm{~cm}$ on day 35 ). Pathological examination of tumor tissues revealed a higher proportion of WB-F344 hepatocytic precursor (stem-like) cells in the co-culture system, as well as a lower karyoplasmic ratio and a lower degree of cellular atypia, compared to the control (Fig. 1). Survival analysis showed that groups A, B, and $C$ had significantly longer life spans compared with group D (Fig. 2, Kaplan Meier survival analysis, $\mathrm{P}<0.05$ ). Taken together, these results show that the tumor formation 


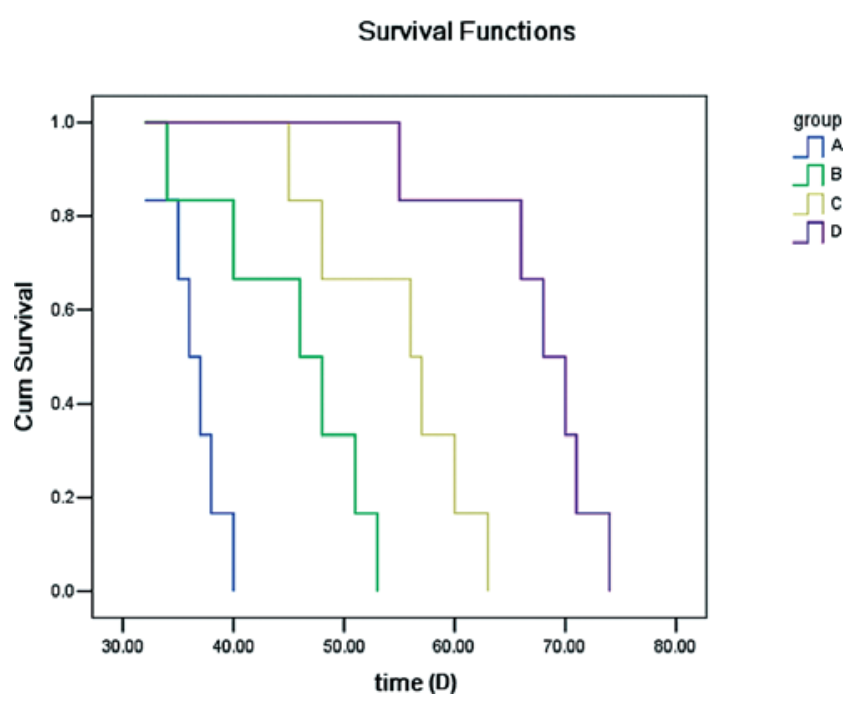

Figure 2. Kaplan-Meier survival analysis of the nude mice that were injected with CBRH-7919 hepatoma cells. Group A: CBRH-7919 control group; group B: CBRH-7919:WB-F344 = 5:1 group; group C: CBRH-7919:WBF344 = 1:1 group; group D: CBRH-7919:WB-F344 = 1:5 group. of the hepatoma cells was inhibited by WB-F344 hepatocytic precursor (stem-like) cells in nude mice.

WB-F344 hepatocytic precursor (stem-like) cells increase apoptosis in CBRH-7919 hepatoma cells. To investigate the mechanisms responsible for the inhibitory effects of WB-F344 hepatocytic precursor (stem-like) cells on tumor formation of the hepatoma cells in nude mice, we determined the apoptotic cells in various settings of the co-culture system using flow cytometry analysis. The apoptotic rates of co-cultured CBRH7919 cells were $13.24,17.08$, and $18.10 \%$ when the co-culture ratios (CBRH-7919:WB-F344) were 5:1, 1:1, and 1:5, respectively (Fig. 3). These figures were significantly higher than that of the CBRH-7919 control cells (12.90\%; Cochran-MantelHaenszel test, $\mathrm{P}<0.05)$, which indicates that the increase in hepatoma cell apoptosis was correlated with the increase in the proportion of the WB-F344 hepatocytic precursor (stemlike) cells in the co-culture system. The decrease in tumor formation and the increase in apoptosis of hepatoma cells were also correlated with the downregulation of BMP4, Bcl-2, and c-Myc and the upregulation of PTEN (Fig. 4).

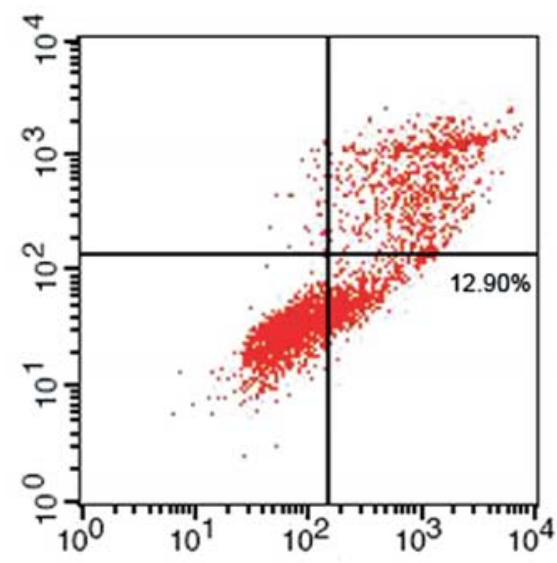

A
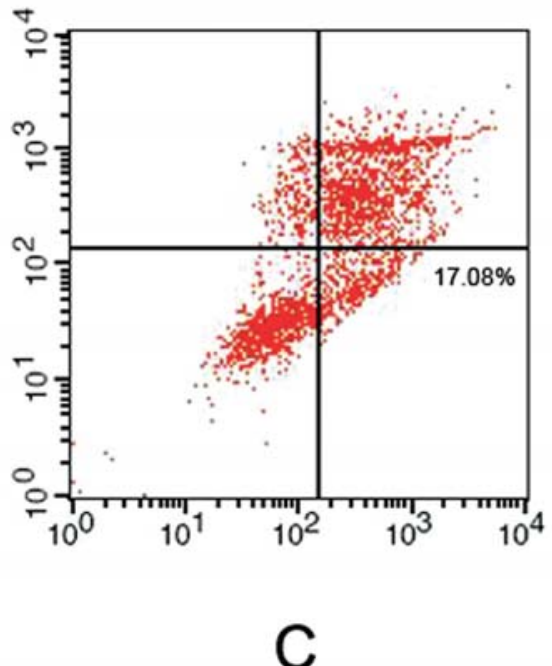

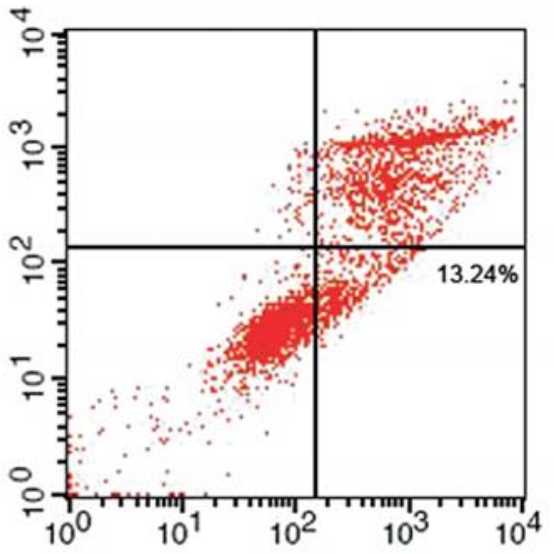

B

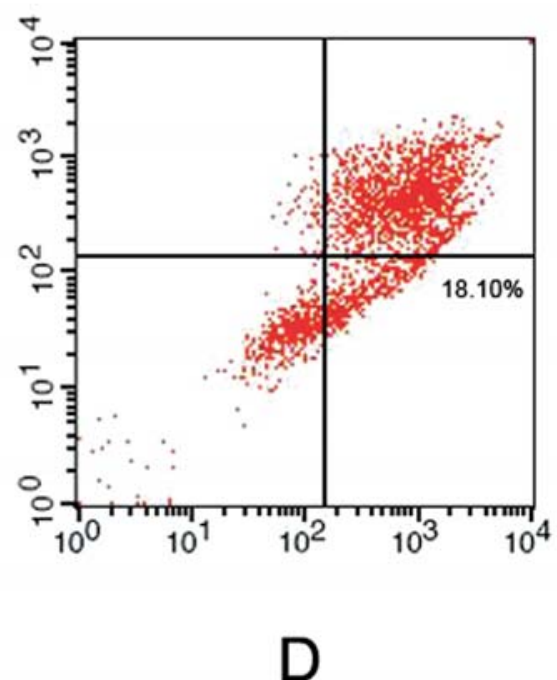

Figure 3. The pro-apoptotic role of the WB-F344 hepatocytic precursor (stem-like) cells on CBRH-7919 hepatoma cells (flow cytometric analysis). The apoptotic rate increased from $12.90 \%$ to $18.10 \%$ when CBRH-7919 cells were co-cultured with WB-F344 cells; that is, the increment in apoptosis was associated with the increased proportion of the WB-F344 hepatocytic precursor (stem-like) cells in the co-culture system. (A) CBRH-7919 control group; (B)

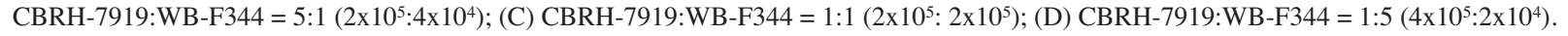




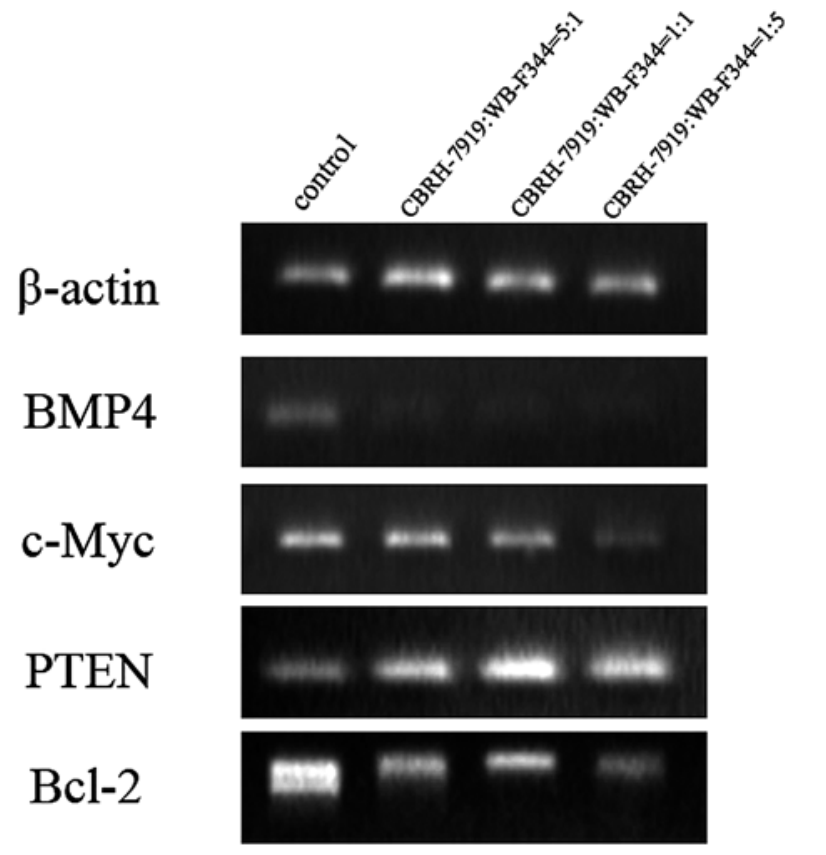

Figure 4. The expression levels of selected genes examined using RT-PCR analysis. The increase in apoptotic rate was associated with downregulation of bone morphogenetic protein 4 (BMP4), Bcl-2, and c-Myc and with upregulation of PTEN levels when the CBRH-7919 cells were co-cultured with WB-F344 cells.

The TGF-ß3/Smad signaling in tumor cells is upregulated by conditioned media in Transwell chamber co-culture system. Since TGF- $\beta$ is an essential regulator of cellular and physiologic processes, including apoptosis $(30,31)$, we propose that the TGF-ß/Smad signal transduction pathway would be involved in governing the inhibitory effect on CBRH-7919 hepatoma cells through its pro-apoptotic role mediated by the WB-F344 hepatocytic precursor (stem-like) cells. As illustrated in Fig. 5, Western blot analyses showed that the treatment of CBRH-7919 hepatoma cells with the increased proportion of WB-F344 cells in the co-culture system resulted in the upregulation of Smad4 and TGF-BRII.

\section{Discussion}

The failure of existing treatments for liver cancer has prompted the search for new methods that can effectively treat cancer cells, including modulating stem cells. In the current study, we demonstrated that the tumorigenicity and apoptosis of hepatoma CBRH-7919 cells was influenced by hepatocytic precursor (stem-like) WB-F344 cells in the co-culture system. Furthermore, the expression levels of several growth/ apoptosis related genes (BMP4, Bcl-2, c-Myc) (32) that represent the malignancy of tumors were downregulated. The TGF- $ß$ superfamily ligands include BMPs (33). Signaling begins with the binding of a TGF- $\beta$ superfamily ligand to a TGF- $\beta$ type II receptor, which recruits and phosphorylates the type I receptor. The type I receptor then phosphorylates receptor-regulated Smads (R-Smads), which can bind the coSmad Smad4. The R-Smad/coSmad complexes accumulate in the nucleus, where they act as transcription factors and participate in the regulation of target gene expression. Finally,

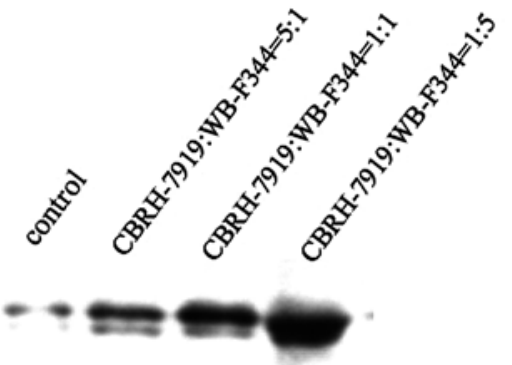

Smad4

\section{GAPDH}

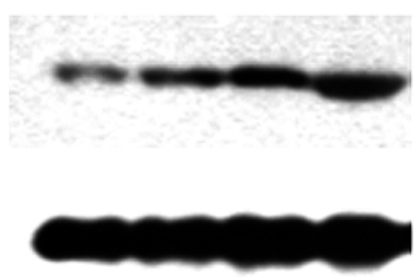

Figure 5. The expression levels of Smad4 and TGF- $\beta$ RII examined by immunoblot analysis. Upregulation of TGF- $\beta$ pathway members such as TGF- $\$$ RII and Smad4 indicate that soluble factors in co-culture conditioned media released from WB-F344 hepatocytic precursor (stem-like) cells might induce tumor cell apoptosis via the TGF- $/$ /smad signal transduction pathway.

the TGF- $\beta$ signaling pathway is involved in many cellular processes, including apoptosis (16). Our findings about the WB-F344 cell inhibitory effects on the tumor formation of hepatoma cells were consistent with other studies of stem cells (34). Our study had two major findings. First, WB-F344 hepatocytic precursor (stem-like) cell treatment increased apoptosis of the co-cultured CBRH-7919 cells. Second, RTPCR and immunoblot analyses showed that the TGF-ß/Smad signaling pathway played a pivotal role in suppressing tumor formation after stem cell treatment.

The selective tropism of liver stem cells to HCC has been reported previously (35), thus stem cells have great therapeutic potential, including as a vector to deliver therapeutic genes for targeted therapy of HCC (36). Mesenchymal stem cells (MSCs) have been identified as bone marrow-derived stem cells, and animal studies have demonstrated that genemodified human MSCs (hMSCs) may serve as a platform for delivery of biological anticancer agents (37). Moreover, unmodified hMSCs can inhibit the growth of tumor cells in vitro, and the homing of hMSCs to sites of hepatocellular carcinoma has been observed, which potently inhibited tumor growth in vivo $(34,38)$ by downregulating certain types of signal transduction pathway, such as the Wnt/B-catenin pathway, by direct cell-cell contact. Other studies suggest that unmodified MSCs are able to home to several different tumor sites in mice and enhance their growth $(39,40)$. Obviously, there are discrepancies about the effects of standard MSCs on tumor cells.

In the present study, we demonstrated the inhibitory capacity of hepatocytic precursor WB-F344 (stem-like) cells on hepatoma cells, which was consistent with the effect of hMSCs on hepatocellular carcinoma $(34,38)$. Although the origins of the cells used in various studies are different, it is generally accepted that stem cells and tumor cells have similar signaling pathways that regulate self-renewal, differentiation, 
and apoptosis, including the Wnt/ß-catenin (41), Notch (42), BMP $(26,43)$, and TGF- $\beta /$ Smad pathways (18). These pathways determine the diverse developmental fates of the cells. According to different differentiation potentials, stem cells can be divided into totipotent stem cells, pluripotent stem cells, and unipotent stem cells (44). Unipotent stem cells, also known as progenitor cells, are limited to differentiating themselves into a specific cell type. The regulation and control mechanisms of different stem cells remain unclear.

Based on our results, we speculate that the TGF- $B / \mathrm{Smad}$ pathway induces apoptosis (caused by unipotent stem cell, WB-F344 cells) and inhibits tumor growth, which is different from the same phenomenon caused by pluripotent stem cells (hMSCs) (34). We believe that, as a result of the different stages of stem cells, the cell signal transduction pathways that control cell growth, differentiation, and apoptosis are different; if the same pathway is involved, the mechanism involved may also be different (45). Studies of the molecular signatures of prostate stem cells also revealed that TGF- $\beta$ has a prominent role in adult stem cells (46), and the Wnt signaling pathway plays a critical role in the regulation of proliferation and in the migration/invasion capacity of hMSCs (47).

In conclusion, we found that the tumor formation of hepatoma cells was inhibited by cytokines that were generated by co-culture with stem cells. Stem cells at different stages may be activated by different pathways, which will be the focus of our future research. Further exploration of how cellcell contact and other factors modulate signaling pathways during carcinogenesis and cancer progression and treatment are required to provide insight into the causes of, and possible treatments for, human hepatocellular carcinoma.

\section{Acknowledgements}

This work was supported by grants from the National Natural Science Foundation of China (No. 30570836 to Hong-Yu Yu).

\section{References}

1. El-Serag HB: Hepatocellular carcinoma: an epidemiologic view. J Clin Gastroenterol 35: S72-S78, 2002.

2. Varela M, Sala M, Llovet JM and Bruix J: Treatment of hepatocellular carcinoma: is there an optimal strategy? Cancer Treat Rev 29: 99-104, 2003.

3. Parkin DM, Bray F, Ferlay J and Pisani P: Estimating the world cancer burden: Globocan 2000. Int J Cancer 94: 153-156, 2001.

4. Morrison SJ and Kimble J: Asymmetric and symmetric stem-cell divisions in development and cancer. Nature 441: 1068-1074, 2006.

5. Fausto N: Liver regeneration: from laboratory to clinic. Liver Transpl 7: 835-844, 2001

6. Michalopoulos GK and DeFrances MC: Liver regeneration. Science276: 60-66, 1997.

7. Paku S, Schnur J, Nagy P and Thorgeirsson SS: Origin and structural evolution of the early proliferating oval cells in rat liver. Am J Pathol 158: 1313-1323, 2001.

8. Bralet MP, Pichard V and Ferry N: Demonstration of direct lineage between hepatocytes and hepatocellular carcinoma in diethylnitrosamine-treated rats. Hepatology 36: 623-630, 2002.

9. Tatematsu M, Kaku T, Medline A and Farber E: Intestinal metaplasia as a common option of oval cells in relation to cholangiofibrosis in liver of rats exposed to 2-acetylaminofluorene. Lab Invest 52: 354-362, 1985.

10. Hixson DC, Affigne S, Faris RA and McBride AC: Delineation of antigenic pathways of ethionine-induced liver cancer in the rat. Pathobiology 64: 79-90, 1996.
11. Hixson DC, Brown J, McBride AC and Affigne S: Differentiation status of rat ductal cells and ethionine-induced hepatic carcinomas defined with surface-reactive monoclonal antibodies. Exp Mol Pathol 68: 152-169, 2000.

12. Yoshida LS, Miyazawa T, Hatayama I, Sato K, Fujimoto K and Kaneda T: Phosphatidylcholine peroxidation and liver cancer in mice fed a choline-deficient diet with ethionine. Free Radic Biol Med 14: 191-199, 1993.

13. Kubota K, Soeda J, Misawa R, et al: Bone marrow-derived cells fuse with hepatic oval cells but are not involved in hepatic tumorigenesis in the choline-deficient ethionine-supplemented diet rat model. Carcinogenesis 29: 448-454, 2008.

14. Livraghi T, Meloni F, Frosi A, et al: Treatment with stem cell differentiation stage factors of intermediate-advanced hepatocellular carcinoma: an open randomized clinical trial. Oncol Res 15: 399-408, 2005.

15. Mishra L, Banker T, Murray J, et al: Liver stem cells and hepatocellular carcinoma. Hepatology 49: 318-329, 2009.

16. Massague J: TGF-beta signal transduction. Annu Rev Biochem 67: 753-791, 1998

17. Massague J and Wotton D: Transcriptional control by the TGFbeta/Smad signaling system. EMBO J 19: 1745-1754, 2000.

18. Nguyen LN, Furuya MH, Wolfraim LA, et al: Transforming growth factor-beta differentially regulates oval cell and hepatocyte proliferation. Hepatology 45: 31-41, 2007.

19..Grasl-Kraupp B, Rossmanith W, Ruttkay-Nedecky B, et al: Levels of transforming growth factor beta and transforming growth factor beta receptors in rat liver during growth, regression by apoptosis and neoplasia. Hepatology 28: 717-726, 1998.

20. Gressner AM, Lahme B, Mannherz HG and Polzar B: TGFbeta-mediated hepatocellular apoptosis by rat and human hepatoma cells and primary rat hepatocytes. J Hepatol 26: 1079-1092, 1997.

21. Amin R and Mishra L: Liver stem cells and tgf-Beta in hepatic carcinogenesis. Gastrointest Cancer Res 2: S27-S30, 2008.

22. Tsao MS, Smith JD, Nelson KG and Grisham JW: A diploid epithelial cell line from normal adult rat liver with phenotypic properties of 'oval' cells. Exp Cell Res 154: 38-52, 1984.

23. Coleman WB, Wennerberg AE, Smith GJ and Grisham JW: Regulation of the differentiation of diploid and some aneuploid rat liver epithelial (stemlike) cells by the hepatic microenvironment. Am J Pathol 142: 1373-1382, 1993.

24. Couchie D, Holic N, Chobert MN, Corlu A and Laperche Y: In vitro differentiation of WB-F344 rat liver epithelial cells into the biliary lineage. Differentiation 69: 209-215, 2002.

25. Zheng X, Shen G, Yang X and Liu W: Most C6 cells are cancer stem cells: evidence from clonal and population analyses. Cancer Res 67: 3691-3697, 2007

26. Maegdefrau U, Amann T, Winklmeier A, et al: Bone morphogenetic protein 4 is induced in hepatocellular carcinoma by hypoxia and promotes tumour progression. J Pathol 218: 520-529, 2009.

27. Yang Y, Zhou F, Fang Z, et al: Post-transcriptional and posttranslational regulation of PTEN by transforming growth factorbeta1. J Cell Biochem 106: 1102-1112, 2009.

28. Takahashi M, Saito H, Okuyama T, et al: Overexpression of Bcl-2 protects human hepatoma cells from Fas-antibodymediated apoptosis. J Hepatol 31: 315-322, 1999.

29. Matsumura I, Tanaka H and Kanakura Y: E2F1 and c-Myc in cell growth and death. Cell Cycle 2: 333-338, 2003.

30. Elliott RL and Blobe GC: Role of transforming growth factor Beta in human cancer. J Clin Oncol 23: 2078-2093, 2005.

31. Breitkopf K, Godoy P, Ciuclan L, Singer MV and Dooley S: TGF-beta/Smad signaling in the injured liver. Z Gastroenterol 44: 57-66, 2006.

32. Silva MT, do Vale A and dos Santos NM: Fish and apoptosis: studies in disease and pharmaceutical design. Curr Pharm Des 14: 170-183, 2008.

33. Kingsley DM: What do BMPs do in mammals? Clues from the mouse short-ear mutation. Trends Genet 10: 16-21, 1994.

34. Qiao L, Xu Z, Zhao T, et al: Suppression of tumorigenesis by human mesenchymal stem cells in a hepatoma model. Cell Res 18: 500-507, 2008

35. Zhong XG, He S, Yin W, Deng JY and Cheng B: Selective tropism of liver stem cells to hepatocellular carcinoma in vivo. World J Gastroenterol 13: 3886-3891, 2007.

36. Chen XC, Wang R, Zhao X, et al: Prophylaxis against carcinogenesis in three kinds of unestablished tumor models via IL12-gene-engineered MSCs. Carcinogenesis 27: 2434-2441, 2006. 
37. Nakamizo A, Marini F, Amano T, et al: Human bone marrowderived mesenchymal stem cells in the treatment of gliomas. Cancer Res 65: 3307-3318, 2005.

38..Qiao L, Zhao TJ, Wang FZ, Shan CL, Ye LH and Zhang XD: NF-kappaB downregulation may be involved the depression of tumor cell proliferation mediated by human mesenchymal stem cells. Acta Pharmacol Sin 29: 333-340, 2008.

39. Studeny M, Marini FC, Dembinski JL, et al: Mesenchymal stem cells: potential precursors for tumor stroma and targeted-delivery vehicles for anticancer agents. J Natl Cancer Inst 96: 1593-1603, 2004.

40. Chiba T, Zheng YW, Kita K, et al: Enhanced self-renewal capability in hepatic stem/progenitor cells drives cancer initiation. Gastroenterology 133: 937-950, 2007.

41. Reya $\mathrm{T}$ and Clevers $\mathrm{H}$ : Wnt signalling in stem cells and cancer. Nature 434: 843-850, 2005.

42. Miele L, Miao $\mathrm{H}$ and Nickoloff BJ: NOTCH signaling as a novel cancer therapeutic target. Curr Cancer Drug Targets 6: 313-323, 2006.
43. Raida M, Heymann AC, Gunther C and Niederwieser D: Role of bone morphogenetic protein 2 in the crosstalk between endothelial progenitor cells and mesenchymal stem cells. Int J Mol Med 18: 735-739, 2006.

44. de Kretser D: Totipotent, pluripotent or unipotent stem cells: a complex regulatory enigma and fascinating biology. J Law Med 15: 212-218, 2007.

45. Wandzioch E and Zaret KS: Dynamic signaling network for the specification of embryonic pancreas and liver progenitors. Science 324: 1707-1710, 2009.

46. Blum R, Gupta R, Burger PE, et al: Molecular signatures of prostate stem cells reveal novel signaling pathways and provide insights into prostate cancer. PLoS One 4: E5722, 2009.

47. Neth P, Ciccarella M, Egea V, Hoelters J, Jochum M and Ries C: Wnt signaling regulates the invasion capacity of human mesenchymal stem cells. Stem Cells 24: 1892-1903, 2006. 